\title{
Research on the Industrial Competitiveness of Beijing Intelligent Connected Vehicle: City Comparison
}

\author{
Ruiyu Feng * and Yingqi Liu \\ School of Economics and Management Beijing Jiaotong University, Beijing, China, 100044 \\ ${ }^{*}$ Corresponding author. Email: 20113075@bjtu.edu.cn
}

\begin{abstract}
Based on the diamond model, this paper constructs the industrial competitiveness evaluation index system of intelligent connected vehicle with 4 first-class indexes, 9 second-class indexes and 16 third-class indexes, and makes an empirical comparative analysis on the relevant data of Beijing, Shanghai and Shenzhen by using entropy method. The results show that, from the perspective of comprehensive index weight, the development of intelligent connected vehicle mainly depends on the investment of capital resources and market demand. From the comprehensive score index, the comprehensive development degree of intelligent connected vehicle in Beijing is the highest, and the main advantages are the strong support of government policies and the outstanding ability of technological innovation. Shenzhen and Shanghai rank second and third. Finally, according to the conclusion of theoretical and empirical research, this paper puts forward some suggestions to promote the development of Beijing intelligent connected vehicle.
\end{abstract}

Keywords: Intelligent connected vehicle, Industrial competitiveness, Diamond model, Entropy method.

\section{INTRODUCTION}

Intelligent connected vehicle (ICV) is the combination of Internet of vehicles and intelligent vehicles. It is a new generation of vehicles which can realize intelligent information exchange and sharing between vehicles and vehicles, roads, people, cloud, etc., and achieve the replacement of human operation ultimately [1]. The emergence of ICV provides a safer, energy-saving, environmental protection and convenient way of travel, plays an important role in both improving driving safety and reducing the driver's burden [2].

China pays high attention to the development of the ICV. The "made in China 2025" clearly takes the ICV industry as a national strategy. As a national science and technology innovation center, Beijing also has a good vehicle industry foundation and perfect industrial system. This paper will build the evaluation index system of ICV industrial competitiveness from the four aspects of production factors, demand conditions, related and supporting industries, and technological innovation, and compare it with Shanghai and Shenzhen, to clarify the advantages and disadvantages of Beijing in the industrial competitiveness of the ICV, so as to optimize the industrial layout and achieve better results development.

\section{LITERATURE REVIEW}

At present, China's research on the ICV industry mainly focuses on the industrial chain, patent technology, road testing and demonstration area construction.

In terms of industrial chain, Li Xiaodong (2019) thinks that the upstream of the ICV industry chain is mainly composed of vehicle manufacturers, and the midstream is the supplier of parts and technology, and the downstream is operation service, and has carried out a detailed interpretation of the various elements of the industrial chain [3].

In terms of patent technology, Zheng Jiabo (2018) uses cloud test platform to discuss the software testing method of ICV, providing theoretical guidance for improving the accuracy and testing efficiency of ICV software test [4]. Jiang Huimin (2019) compares global ICV patent technology from the perspective of technology field and technology life cycle [5]. 
In terms of road test and demonstration area construction, Zhu Yueyan (2018) clarifies the operation subject and functional orientation of the test demonstration area, and promoted the industrialization process of ICV [6]. Yu Shengbo (2020) puts forward suggestions for the development of China's ICV in the aspects of road test process, scene, accident liability determination, commercial insurance and international cooperation [7].

In terms of industrial competitiveness, the most common analysis framework is Porter's "Diamond Model". He believes that the four core elements affecting industrial competitiveness are production factors, demand conditions, related industries and supporting industries, enterprise strategy, enterprise structure and peer competition. Opportunity and government are also two factors that can't be ignored. These six elements interact and interact with each other Supplement [8].

Among the evaluation methods of industrial competitiveness, entropy method is used in the empirical calculation of industrial competitiveness evaluation index weight. It judges the dispersion degree of this index according to the information provided by each observation value [9]. The greater the dispersion degree, the greater the influence of the index on the comprehensive evaluation.

To sum up, the existing research is mainly aimed at a certain link in the development process of the ICV industry. There are few literatures on exploring the competitiveness of the industry from the whole industry level, and most of the researches are qualitative analysis, lacking in quantitative evaluation and index selection.

\section{CONSTRUCTION OF EVALUATION INDEX SYSTEM}

\subsection{Model Building}

Based on the theory of "Diamond Model", this paper selects three core elements: production factors, demand conditions, related and supporting industries. According to the characteristics of the ICV industry, it adds the elements of technological innovation and constructs a new diamond model to compare and evaluate the competitiveness of Beijing's ICV industry, as shown in Figure 1.

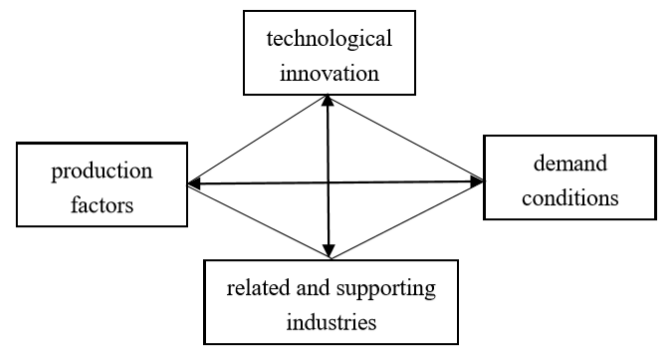

Figure 1 Model framework.

After comprehensively considering the representativeness of the indexes and the collectability of the data, 4 first-class indexes, 9 second-class indexes and 16 third-class indexes are selected to construct the industrial competitiveness evaluation index system of Beijing's ICV industry as shown in Table 1.

Table 1. Index evaluation system

\begin{tabular}{|c|c|c|}
\hline First-class index & Second-class index & Third-class index \\
\hline & Human capital & $\begin{array}{c}\text { Proportion of R\&D } \\
\text { employees to employees }\end{array}$ \\
\hline & & The number of students in colleges \\
\hline \multirow[t]{4}{*}{ production factors } & Capital resources & GDP growth rate \\
\hline & & R\&D expenditure \\
\hline & Hardware and software facilities & Government support \\
\hline & Demand quantity & Total population \\
\hline \multirow[t]{4}{*}{ Demand conditions } & & Car ownership \\
\hline & Potential demand & Per capital GDP \\
\hline & & $\begin{array}{l}\text { Growth rate of per capita } \\
\text { disposable income }\end{array}$ \\
\hline & Raw material supply & $\begin{array}{l}\text { Number of main engine plants } \\
\text { and parts enterprises }\end{array}$ \\
\hline \multirow[t]{3}{*}{$\begin{array}{l}\text { Related and supporting } \\
\text { industries }\end{array}$} & & $\begin{array}{l}\text { Growth rate of vehicle manufacturing industry above } \\
\text { designated size }\end{array}$ \\
\hline & High-tech industry & $\begin{array}{l}\text { Number of intelligent } \\
\text { technology providers }\end{array}$ \\
\hline & Product patent & Number of patent applications \\
\hline \multirow[t]{3}{*}{$\begin{array}{l}\text { Technological } \\
\text { innovation }\end{array}$} & & Patent growth rate \\
\hline & R\&D units & Number of universities \\
\hline & & Number of Internet enterprises \\
\hline
\end{tabular}




\subsection{Data Selection}

This paper takes Beijing, Shanghai and Shenzhen as the research objects, and uses Excel to analyze the data by entropy method. In order to ensure the reliability and accuracy of the data, this paper collects the index data of Beijing, Shanghai and Shenzhen in 2018. The data comes from the summary of the National Bureau of statistics, China statistical information network, China Automobile Industry Association, China Industrial Information Network and statistical yearbooks of various provinces and cities. Three enterprises in Beijing were investigated on the spot and interviewed to obtain the data, and finally obtained the three-level index data.

\subsection{Evaluation Method}

In this paper, the entropy method is used to calculate the competitiveness of the industry. Entropy method is an objective weighting method, which avoids the deviation caused by human factors and ensures the scientificity and rationality of the analysis [10]. The calculation steps are as follows:

(1) Dimensionless data processing

$C_{i j}=\frac{x_{i j}-\min _{j} X_{i j}}{\max _{j} X_{i j}-\min _{j} X_{i j}}(\mathrm{I}=1,2, \ldots, \mathrm{N} ; \mathrm{j}=1,2, \ldots, \mathrm{M})$

$X_{i j} \in \mathrm{X}$ represents the value of the I city on the $\mathrm{j}$
(2) Data normalization

$$
P_{i j} \quad=\quad \frac{C_{i j}}{\sum_{i=1}^{N} C_{i j}} \quad(\mathrm{j}=1,2, \ldots, \mathrm{M})
$$

(3) Calculate the entropy of the index

$E_{j} \quad=\quad-\mathrm{K} \quad \sum_{i=1}^{N} P_{i j} \ln P_{i j} \quad\left(\mathrm{~K}>0, \quad E_{i} \quad>0\right)$

(4) Calculate the difference coefficient of index

$\begin{array}{lllllll}D_{j} & = & 1 & - & E_{j} & ,(\mathrm{j}=1,2, \ldots, \mathrm{M})\end{array}$

(4) Calculate the weight of evaluation index

$W_{j} \quad=\quad \frac{D_{j}}{\sum_{j=1}^{M} D_{j}} \quad,(\mathrm{j}=1,2, \ldots, \mathrm{M})$

(6) Calculate the comprehensive competitiveness score of each city

$S_{i}$

(6)

$$
\sum_{j=1}^{M} W_{j}
$$

\section{RESULT ANALYSIS}

\subsection{Weight Analysis of Evaluation Index}

After dimensionless processing of the data, according to formula (2) - (5), the weight values of each three-level index corresponding to the three cities' intelligent network connected automobile industry are calculated, as shown in Table 2.

\begin{tabular}{|c|c|c|c|c|}
\hline Third-class index & $\operatorname{Entropy}\left(E_{j}\right)$ & Coefficient of variation $\left(D_{j}\right)$ & Weight $\left(W_{j}\right)$ & Weight ranking \\
\hline $\begin{array}{c}\text { Proportion of R\&D } \\
\text { employees to employees }\end{array}$ & 0.963811 & 0.036189 & $5.78 \%$ & 10 \\
\hline The number of students in colleges & 0.955352 & 0.034648 & $5.53 \%$ & 14 \\
\hline GDP growth rate & 0.946395 & 0.053605 & $8.56 \%$ & 1 \\
\hline R\&D expenditure & 0.961386 & 0.038614 & $6.16 \%$ & 6 \\
\hline Government support & 0.962970 & 0.037030 & $5.91 \%$ & 7 \\
\hline Total population & 0.964493 & 0.035507 & $5.67 \%$ & 11 \\
\hline Car ownership & 0.959857 & 0.040143 & $6.41 \%$ & 4 \\
\hline Per capital GDP & 0.952011 & 0.047989 & $7.66 \%$ & 3 \\
\hline $\begin{array}{c}\text { Growth rate of per capita } \\
\text { disposable income }\end{array}$ & 0.962970 & 0.037030 & $5.91 \%$ & 7 \\
\hline $\begin{array}{l}\text { Number of main engine plants } \\
\text { and parts enterprises }\end{array}$ & 0.961254 & 0.038746 & $6.18 \%$ & 5 \\
\hline $\begin{array}{l}\text { Growth rate of vehicle manufacturing } \\
\text { industry above designated size }\end{array}$ & 0.963613 & 0.036387 & $5.81 \%$ & 9 \\
\hline $\begin{array}{l}\text { Number of intelligent } \\
\text { technology providers }\end{array}$ & 0.965110 & 0.034890 & $5.57 \%$ & 13 \\
\hline Number of patent applications & 0.964640 & 0.035360 & $5.64 \%$ & 12 \\
\hline Patent growth rate & 0.948359 & 0.051641 & $8.24 \%$ & 2 \\
\hline Number of universities & 0.965848 & 0.034152 & $5.45 \%$ & 16 \\
\hline Number of Internet enterprises & 0.965446 & 0.034554 & $5.52 \%$ & 15 \\
\hline
\end{tabular}

Table 2. Weight of evaluation index 
Through the analysis of the weight of each evaluation index in the table above, we can get the following conclusions:

\subsubsection{Capital Resources Contribute the Most to the Industrial Competitiveness of the ICV}

Among the 16 indexes, GDP growth rate accounts for the largest weight, accounting for $8.56 \%$, which shows that China's economic development environment, has a great impact on the industrial competitiveness of the ICV, and the growth of the industry also plays a leading role in China's economic development. Meanwhile, $R \& D$ expenditure ranked the sixth in weight. The increase of $R \& D$ expenditure means more and more investment in R\&D materials and technology, which provides a strong guarantee for the improvement of innovation strength. The capital resources represented by GDP growth rate and $\mathrm{R} \& \mathrm{D}$ expenditure play a fundamental role in promoting the development of the ICV industry.

\subsubsection{Consumption Drives Demand and Stimulates the Development of ICV Industry}

It can be seen from the table that the weight of per capita GDP is $7.66 \%$, ranking the third, and the weight of car ownership is $6.41 \%$, ranking the fourth. Thus, the per capita GDP and car ownership of the three cities contribute greatly to the development of the ICV industry, which is consistent with the current economic development situation of China. The improvement of people's consumption level can promote the development of ICV industry and form the path of consumption driving demand. Meanwhile, China's broad vehicle application market and good industrial foundation also lay the foundation for the development of ICV.

\subsubsection{The Development of Related Industries does not Promote the Industrial Competitiveness of ICV}

In the table, the weight of intelligent technology providers is $5.57 \%$, ranking the 13th; the weight of Internet enterprises is $5.52 \%$, ranking 15 th; the weight of colleges is $5.45 \%$, ranking 16th. It can be seen that the cooperation mode between the ICV industry and the science and technology industry, education industry, Internet industry and vehicle manufacturing enterprises are not good enough, and the collaborative development effect is low. Although there are many raw material enterprises, technology providers and scientific research institutes, these resources are not integrated, which affects the development of ICV industry.

\subsubsection{The Transformation of Innovation Achievements has a Great Impact on the Industrial Competitiveness of ICV}

It can be seen that the weight of patent growth rate is $8.24 \%$, ranking the second; while the weight of patent application is only $5.64 \%$, ranking the 12 th, which shows that with the continuous improvement of China's scientific and technological strength, enterprises pay more and more attention to patent application, and the transformation rate of patent achievements is gradually accelerated. However, the contribution of patent application to the industrial competitiveness of ICV is low, and the low R\&D efficiency is also a big problem.

\subsection{Analysis of Comprehensive Score Index}

After calculating the weight of each index by entropy method, the 16 index data are weighted to obtain the first level index scores of Beijing, Shanghai and Shenzhen, as well as the comprehensive score and ranking of the industrial competitiveness of each city's ICV. As shown in Table 3 and Figure 2.

Table 3. First-class index and comprehensive competitiveness score

\begin{tabular}{|c|c|c|c|c|c|c|}
\hline $\begin{array}{c}\text { First-class } \\
\text { index }\end{array}$ & $\begin{array}{c}\text { Production } \\
\text { factors }\end{array}$ & $\begin{array}{c}\text { Demand } \\
\text { conditions }\end{array}$ & $\begin{array}{c}\text { Related and } \\
\text { supporting industries }\end{array}$ & $\begin{array}{c}\text { Technological } \\
\text { innovation }\end{array}$ & $\begin{array}{c}\text { Comprehensive } \\
\text { competitiveness } S_{i}\end{array}$ & Ranking \\
\hline Beijing & 0.119045 & 0.098975 & 0.061238 & 0.089552 & 0.368811 & 1 \\
\hline Shanghai & 0.104565 & 0.079349 & 0.054833 & 0.070331 & 0.309078 & 3 \\
\hline Shenzhen & 0.095790 & 0.078176 & 0.059529 & 0.088617 & 0.322112 & 2 \\
\hline
\end{tabular}




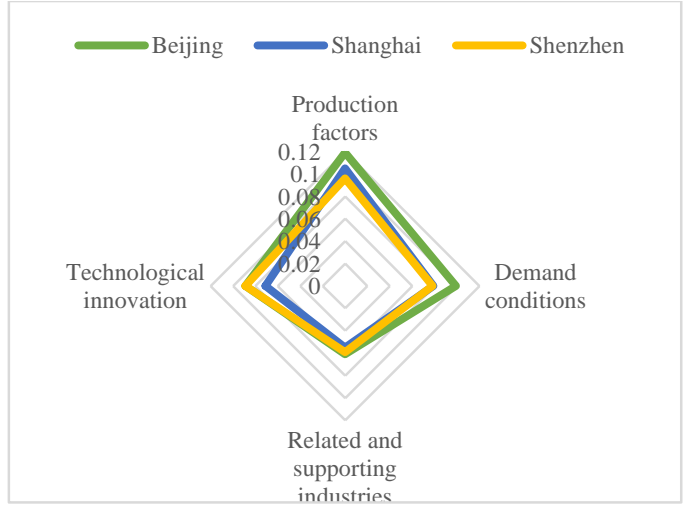

Figure 2 Radar chart of first level index score.

It can be seen that production factors, demand conditions and technological innovation are more important and have a higher influence on the development of ICV industry. Among them, Beijing has no obvious short board and its development in all aspects is balanced; Shanghai is slightly insufficient in technological innovation, while Shenzhen has certain defects in production factors.

According to the comparison of the three cities, it can be seen that Beijing has the highest score in the competitiveness of its industry, with strong comprehensive development ability, followed by Shenzhen, and Shanghai ranked third.

\subsubsection{Production Factors}

Beijing scored 0.119, ranking first among the three cities. The main advantages are reflected in the number of college students, R\&D expenditure and policy support. This shows that Beijing has competitive advantages in terms of human capital, capital resources, software and hardware facilities, and has relatively perfect production conditions for the intelligent connected automobile industry.

\subsubsection{Demand Conditions}

Beijing's score is the highest among the three cities, with obvious advantages in terms of car ownership and per capita disposable income. It can be seen that Beijing has a strong market demand in the ICV industry, and its automobile consumption is mainly reflected in the direction of electric, intelligent and networked development.

\subsubsection{Related and Supporting Industries}

Beijing scored 0.061, and its competitive advantage was not obvious compared with Shanghai and Shenzhen. Although Beijing has certain advantages in the number of intelligent technology providers and main engine and parts enterprises, due to the influence of political factors, the automobile manufacturing industry has gradually moved out, and the automobile manufacturing industry above the scale has a negative growth rate.

\subsubsection{Technological Innovation}

Beijing scored 0.090, ranking first among the three cities. Compared with Shanghai and Shenzhen, Beijing has a strong competitive advantage, which is mainly reflected in the number of well-known universities and Internet enterprises. Although there are many institutions involved in technology R\&D in Beijing, the speed of innovation achievement transformation is slow, which is far behind that of Shenzhen and Shanghai.

\section{CONCLUSION AND SUGGESTION}

\subsection{Conclusion}

In this paper, the diamond model is used as the analysis framework, and the index evaluation system of industrial competitiveness is constructed. The entropy method is used to compare the development status of the ICV industry in Beijing, Shanghai and Shenzhen, and the index data is calculated. From the comprehensive index weight point of view, the development of the ICV industry mainly depends on the investment of capital resources and the market demand. From the comprehensive score index, the competitiveness ranking of the ICV industry from high to low is: Beijing, Shenzhen and Shanghai.

As the national political center, cultural center and scientific and technological innovation center, the demand conditions and technological innovation are the advantages of Beijing's ICV industry competitiveness, while the advantages of production factors and related and supporting industries are not obvious. Therefore, in the process of the development of the ICV industry, on the basis of maintaining the advantages of technological innovation and demand conditions, Beijing continues to enhance the competitiveness of relevant and supporting industries, attaches importance to the development of supporting industries, and expands the input of production factors, so as to lead the transformation and development of the ICV industry with technological innovation and upgrading.

\subsection{Suggestion}

\subsubsection{Promote the Development of Industrial Collaborative Innovation, and Strengthen Industrial Alliance Cooperation}

The development of ICV industry is related to the government, vehicle manufacturing industry, Internet enterprises, scientific research institutions, universities and so on, which cannot be separated from the support 
of various conditions. Beijing has a complete automobile industry system, strong upstream, midstream and downstream enterprises of ICV, led by BAIC group and Baidu company. Because of numerous scientific research institutes, it has outstanding advantages in educational resources. In order to promote the development of ICV industry, it is necessary to integrate the resources of the government, enterprises, universities and scientific research institutions, make use of the advantages of Beijing in production factors and demand conditions to form an inter industry alliance, and participate in the development strategy of industrial collaborative innovation.

\subsubsection{Enhance the Capability of Independent Technological Research and Accelerate the Innovation of Key Technologies}

Intellectualization and networking are the two core technologies of ICV. As a national science and technology innovation center, Beijing has obvious advantages in technological innovation. At present, the technical difficulties of the ICV industry mainly focus on the fields of Internet of vehicles technology, high-precision maps, high-precision sensors and high-performance integrated computing [11]. Therefore, Beijing should make use of the advantages of regional innovation ability, integrate existing resources, and study key technologies, so as to reduce the industry's dependence on imported raw materials and foreign core technologies high independent R\&D ability and control ability for key technologies.

\subsubsection{Promote the Construction of Application Demonstration Site and Clarify the Test and Evaluation Standards}

The construction of the application demonstration area plays a supporting role in the test and development of ICV industry. At present, Beijing has two closed self-driving test fields. However, with the improvement in both test level and technology of vehicles, Beijing needs to further expand the test scope and application scenarios of ICV. In addition to simulating various road scenes, traffic scenes and complex weather environment, the demonstration area should be gradually opened to speed up the industrialization process of intelligent connected vehicles. In addition, a clear test and evaluation standard is helpful to better understand the performance of ICV in terms of safety, riding experience, energy consumption and efficiency, so as to effectively promote the development of ICV industry.

\section{REFERENCES}

[1] China Society of automotive engineering. Energy saving and new energy vehicle technology roadmap [M] Beijing: China Machine Press, 2016.

[2] Li Keqiang, Dai Yifan, et al. Development status and trend of ICV technology $[\mathrm{J}]$. Journal of automotive safety and energy conservation, 2017, 8 (1): $1-14$.

[3] Li Xiaodong, Li Hongqing, Zhang min. research on the industrial chain of ICV [J]. Motorcycle technology, 2019 (09): 37-40.

[4] Zheng Jiabo, Chen Zhuo. Research on software testing technology of ICV based on cloud platform [J]. Automotive electronics, 2018 (12): 21-25.

[5] Jiang Huimin, Cui Ying, et al. Research on the technology development trend of ICV in major countries (regions) in the world based on patent analysis $[\mathrm{J}]$. Science and technology management research, 2019 (24): 119-127.

[6] Zhu Yueyan, Zhao Lin. analysis and suggestions on the development of domestic ICV test and demonstration zone [J]. Automotive industry research, 2018 (11): 36-43.

[7] Yu Shengbo, Chen Guihua, Li Qiao, et al. Comparative study on road test of ICV at home and abroad [J]. Automotive abstracts, 2020 (2): 29-36.

[8] Michael Porter. National competitive advantage. Trans. Li Mingxuan and Qiu Rumei [M]. Beijing: CITIC press, 2012:64-65.

[9] Tang Wenbin, Han Zhijun. Comprehensive financial evaluation method based on entropy method [J]. Journal of Nanjing University of technology, 2001, 25 (6): 650-653.

[10] Xu Fenfen. Evaluation of regional innovation capability in China based on entropy method [D]. Shenyang University of technology, 2013.

[11] Tang Sijia. Analysis on the development planning and development policy of China's intelligent Internet connected automobile industry [J]. Era automobile, 2019, (20): 101-102. 